\title{
Emergency referral transport for maternal complication: lessons from the community based maternal death audits in Unnao district, Uttar Pradesh, India
}

\author{
Sunil Saksena Raj ${ }^{1 *}$, Suneedh Manthri ${ }^{1}$, Pratap Kumar Sahoo ${ }^{2}$
}

\begin{abstract}
Background: An effective emergency referral transport system is the link between the home of the pregnant woman and a health facility providing basic or comprehensive emergency obstetric care. This study attempts to explore the role of emergency transport associated with maternal deaths in Unnao district, Uttar Pradesh (UP).

Methods: A descriptive study was carried out to assess the causes of and factors leading to maternal deaths in Unnao district, UP, through community based Maternal Death Review (MDR) using verbal autopsy, in a sample of 57 maternal deaths conducted between June 1, 2009, and May 31,2010. A facility review was also conducted in 15 of the 16 block level and district health facilities to collect information on preparedness of the facilities for treating obstetric complications including referral transportation. A descriptive analysis was carried out using ratios and percentages to analyze the availability of basic facilities which may lead to maternal deaths.

Results: It was found that there were only 10 ambulances available at 15 facilities against 19 required as per Indian Public Health Standards (IPHS). About $47 \%$ of the deaths took place in a facility, $30 \%$ enroute to a health facility and $23 \%$ at home. Twenty five percent of women were taken to one facility, $32 \%$ were taken to two facilities, and $25 \%$ were taken to three facilities while $19 \%$ were not taken to any facility before their death. Sixteen percent of the pregnant women could not arrange transportation to reach any facility. The mean time to make arrangements for travel from home to facility- 1 and facility- 2 to facility- 3 was 3.1 hours; whereas from facility- 1 to facility-2 was 9.9 hours. The mean travel time from home to facility- 1 was 1 hour, from facility- 1 to facility- 2 was 1.4 hours and facility- 2 to facility-3 was 1.6 hours.

Conclusion: The public health facility review and MDR, clearly indicates that the inter-facility transfers appropriateness and timeliness of referral are major contributing factor for maternal deaths in Unnao district, UP. The UP Government, besides strengthening Emergency Obstetric and Newborn Care (EmONC) and Basic Emergency Obstetric and Newborn Care (BEmONC) services in the district and state as a whole, also needs to focus on developing a functional and effective referral system on a priority basis to reduce the maternal deaths in Unnao district.

Keywords: Referral Transport, Maternal Deaths, Facility Review, Maternal Death Review (MDR)

Copyright: $\odot 2015$ by Kerman University of Medical Sciences

Citation: Raj SS, Manthri S, Sahoo PK. Emergency referral transport for maternal complication: lessons from the community based maternal death audits in Unnao district, Uttar Pradesh, India. Int J Health Policy Manag 2015; 4: 99-106. doi: 10.15171/ijhpm.2015.14
\end{abstract}

Article History:

Received: 26 August 2014 Accepted: 8 January 2015 ePublished: 14 January 2015

\footnotetext{
${ }^{*}$ Correspondence to:

Sunil Saksena Raj

Email: sunil.sraj@phfi.org
}

\section{Key Messages}

Implications for policy makers

- Emergency referral transport is a crucial component of Emergency Obstetric and Newborn Care (EmONC). The state may have to invest in assuring the availability of functional ambulance attendant on a round the clock basis. The attendant needs to be trained in Cardiopulmonary Resuscitation (CPR) and basic emergency care to avoid death during transportation.

- Early availability of transport for referral to higher health facility should be ensured at lower health facility for rapid availability of intervention to save maternal lives.

- The referral of mother from one facility to other needs to be done only after ensuring the availability of required services at the referred health facility, e.g. blood transfusion, surgical services, etc. Otherwise, referral may be made directly to the next higher facility or district hospital.

Implications for public

There has been a great deal of emphasis on community education in the Safe Motherhood Initiative (SMI). Underlying many of these efforts is the assumption that there is something that the community should be doing to avert many of these deaths, such as, recognizing the complication sooner or seeking care sooner. What is clear from this study, is that the most important factor in the deaths of these women is the distance they must travel to find a facility that is actually providing life-saving care, whether basic or comprehensive Emergency Obstetric and Newborn Care (EmONC). 


\section{Background}

Globally Maternal Mortality Ratio (MMR) declined from 400 maternal deaths per 100,000 live births in 1990 to 210 in 2010 (1). All developing regions experienced a decline in MMR between 1990 and 2010, with the highest reduction in the last 20 -year period. India accounts for about $19 \%$ of the global maternal deaths. As to reduce MMR by three quarters, that is 109 per 100,000 live births by 2015, the MMR in India was trailing by 103 per 100,000 live births to achieve Millennium Development Goal 5 (MDG 5) by the year 2015 (2,3). MMR in India for period 2007-10 was 212 per 100,000 live births, with values ranging from 81-390 across different states of the country. Uttar Pradesh (UP) accounts for 19\% of the India's population and has second highest MMR of 359 per 100,000 live births after Assam (4). The leading causes of maternal deaths in India are hemorrhage (38\%), sepsis (11\%) and abortion (8\%), and UP follows the same pattern and most of these deaths are preventable (4).

Since the launch of the National Rural Health Mission (NRHM) in 2005, there has been a substantial increase of $30 \%$ in the institutional deliveries across the country except for few states $(5,6)$. In UP, the institutional delivery rate has increased steadily from $11 \%$ to $15 \%$ to $22 \%$ [National Family Health Survey (NFHS)-1, NFHS-2, and NFHS-3]; however, it is still extremely low as against the national average of $41 \%$ (7). Many pregnant women in UP were not receiving the care and treatment required for safe deliveries and only $20 \%$ of the population is using the public health infrastructure (8). According to the India facility survey 2010, UP had 1,293 Community Health Centers (CHCs) in place, but there were only 515 (40\%) functional CHCs and all of them 100\% CHCs (i.e. 515 CHCs) had referral transport service in place (9). This was in complete contrast to our study about the public referral transport services in Unnao district, UP.

In the guidelines related to availability and distribution of Emergency Obstetric and Newborn Care (EmONC) services, it is recommended that at least five EmONC facilities [4 Basic EmONC (BEmONC) and 1 Comprehensive EmONC (CEmONC)] be available per 500,000 population and distributed geographically (10). To establish a responsive emergency referral system and the transportation mechanisms to safely transfer a woman from a site of complication to a definite level of care (health facility and further referrals) needs clinical judgment, stabilization and transfer protocols, communications technology, transportation, and cost arrangements. Reliable transportation is always a missing link to timely, accessible and affordable emergency care (10-12).

\section{Definitions}

Referral is the coordinated movement of healthcare seekers through the health system to reach a high level of care in a small and often fatal window of time (13). Goal of referral transport is to address the second delay and also to provide pre-hospital care while transporting patient to appropriate hospital (public/ private) (See Box 1) (12,14,15).

Public referral transport includes either a government owned or an out sourced transport through Public Private Partnership (PPP) to operate and provide the referral transport services (16). The three delays framework: the delay in recognizing complications before, during and after delivery; the delay in accessing skilled care to address complications; and the delay

\section{Box 1. Features of referral transport has to be:}

1) Should be available within 30 minutes and be able to take the women or newborn to a referral site within one hour.

2) Transport may be: a) an ambulance with the facility, b) an ambulance called from the higher facility, c) an ambulance service, or d) a private or commercial transport vehicle.

3) Communication contact with the vehicle driver directly or routed through a call center

4) The ambulance service should be free of cost at the time of need

Source: (16)

in receiving quality care, is an internationally recognized framework for maternal deaths $(10,17)$. Evidence suggests that, addressing the $2^{\text {nd }}$ delay has significant role in reducing the maternal mortality $(11,17)$.

The objective of this paper is to study evidence and argue for improving access and availability of functional referral transport system. This paper also address the second delay through community based Maternal Death Review (MDR) and public health facility review conducted in Unnao district, UP in 2010 .

\section{Methods}

\section{Study setting}

In 2010, UP had an MMR of 359 per 100,000 live births, which is the second highest in the country, and is way above the national average MMR of 212, UP also has a significantly high IMR than the national average (79 vs. 59) (18). Unnao district in UP was selected as study district based on the grading of the districts provided by Jansankhya Sthirta Kosh (JSK), a registered autonomous society of the Ministry of Health and Family Welfare (MoHFW, India). The grading of the district is based on a composite index of 13 socio-economic and demographic indicators, including the percentage of women having three or more children, contraceptive prevalence, under-five mortality rate, and the percentage of women having three or more antenatal visits. Unnao district was ranked at $48^{\text {th }}$ position out of 70 districts based on this composite index ranking (19). Unnao district is geographically placed between two cities, Lucknow and Kanpur, with an assumption it would have better access to EmONC services.

Unnao district had a population of 3.1 million, which is $1.5 \%$ of the state's population (20). Other health indicators for the year 2011 were: birth rate $=22.2$ per 1,000 people; estimated number of annual births $=69,055$; number of institutional deliveries $=14,488$; estimated number of maternal deaths $=248$ per 100,000 live births (21). The female literacy was $57 \%$; total fertility rate was $2.58(20)$. There are 16 health facilities, of which seven were providing $24 \times 7 \mathrm{CEmONC}$ services: [four $\mathrm{CHCs}$; two CHCs designated as First Referral Units (FRUs); and one district hospital], and the remaining nine block Primary Health Centers (PHCs) were providing $24 \times 7$ BEmONC services.

\section{Study design}

This is a descriptive study which aims to capture the role of referral transport leading to maternal deaths. Health facility review was undertaken in 15 of the 16 public health facilities and community based MDR was also conducted in a sample 
of maternal deaths identified between the period 1 June, 2009 to 31 May, 2010, from various sources, in Unnao district, UP.

\section{Study population}

Public health facility review

There were total of 16 public health facilities in Unnao district. A team of six physicians conducted facility assessments in 15 out of 16 health facilities in Unnao district. The health facilities assessed include eight block level PHC's, four CHCs, two CHCs designated as FRUs, and one district hospital. The district hospital, CHCs and CHCs designated as FRUs for providing CEmONC services, while the block PHCs are supposed to be providing BEmONC services. One block PHC (Achalganj) was not assessed as it is very close to Kanpur and most of the maternity cases avail the facility at Kanpur rather than PHC Achalganj.

\section{Maternal Death Review (MDR)}

The existing government maternal death reporting form was distributed to key informants' Anganwadi Workers (AWWs), Auxiliary Nurse Midwives (ANMs) and Accredited Social Health Activists (ASHAs). The ANMs and ASHAs work under the Department of Health and Family Welfare while, the AWWs work under the Department of Women and Child Development. ASHAs are community health workers instituted by the government of India's MoHFW as part of the NRHM (22). Maternal death reporting forms were distributed to around 265 ANMs and ASHAs, and 2,573 AWWs during their weekly visits to the PHC and monthly meetings. These key informants were then asked to report information on all female deaths in the age group of 15-49 years, reported in Unnao district during 1 June, 2009 to 31 May, 2010. Information on maternal deaths was also sought from the health facilities. The key informants reported a total of 207 maternal deaths from all the blocks in Unnao district, excluding the 2 urban blocks of Shuklaganj and Unnao City. Of these 207 deaths that occurred during the study period June 1, 2009 and May 31, 2010, we identified 153 (62\%) as maternal deaths. AWWs reported all 153 maternal deaths. ANMs and ASHAs reported only 107 maternal deaths out of the total identified maternal deaths (153). We validated $10 \%$ of key informants' maternal death reports with families either through in person visits or by telephone. Of the 153 deaths occurring during the study period, we randomly selected a sample of 70 maternal deaths, proportionate to the deaths in each block, to conduct verbal autopsies. Verbal autopsy questionnaire was administered to relatives of only 57 death cases, as seven deaths were subsequently not found to be related to pregnancy or childbirth, two were outside the study period, insufficient information was available for two cases while two cases could not be traced. In each case, a cause of death was assigned by a panel of three obstetricians.

\section{Data collection and analysis}

A standardized tool was developed to conduct in health facility review, for assessing their preparedness to manage emergency obstetric complications (23). This review was carried out by a team of six trained medical doctors. A modified Maternal and Perinatal Death Inquiry and Response (MAPEDIR) tool: a detailed verbal autopsy questionnaire was used in carrying out the community based MDR to capture factors and processes leading to these deaths (24). The verbal autopsy was collected by a team of six medical doctors. The completed verbal autopsy forms were reviewed by 2 obstetricians who independently assigned probable cause of death, based on available information recorded in the questionnaires related to history, events, and symptoms. If the diagnoses of the 2 obstetricians matched, we considered the diagnosis final. In cases of disagreement, a third obstetrician reviewed the form, and we considered her diagnosis final. The data was collected by six trained social researchers in the field for about three weeks.

A detailed methodology has been reported separately by the authors including detailed sample selection strategy and data collection methods was published elsewhere (25). Descriptive analysis was carried out to represent the facility review data. Bivariate analysis using percentages was undertaken, with a $P<0.05$ considered as significant for the MDR data. All the data was analyzed using SPSS 17 (SPSS Inc., Chicago, IL, USA). We also reviewed literature on other referral transport models available in India and elsewhere, we have culled out evidence on effectiveness of the referral transport system to reduce the time in transporting the pregnant women to a health facility, in order to save maternal lives.

\section{Results}

Findings from the public health facility review

In the public health facility review, it was found that there were only 10 ambulances available at 15 facilities as against 19 required as per Indian Public Health Standards (IPHS) guidelines. Only 8 out of 15 facilities had ambulances in working order, had at least 1 driver, and had funds available for fuel and maintenance of this skeletal service arrangement (see Table 1). None of the facilities were not offering regular, roundthe-clock referral transport services including the district hospital at Unnao district head quarter.

\section{Findings from the Maternal Death Review (MDR)}

The demographic characteristics of the identified maternal deaths in this study, $74 \%$ of the women were more than 25 years of age at the time of death, and $28 \%$ of the women got married before they were 18 years of age. Fifty four percent of the deceased women and $46 \%$ of husbands were illiterate (Table 2 ). The maternal deaths as identified by a team of three obstetricians from the verbal autopsy. Postpartum hemorrhage was identified as a cause (39\%), while other causes were severe anemia (26\%), sepsis (14\%), pregnancy induced hypertension, eclampsia, and obstructed labour (18\%) while no cause could be identified in (3\%) (Figure 1).

Poor access to transportation services resulted in delays that appear to have contributed significantly to maternal deaths as identified in our study. Of the 57 maternal deaths, 48 women died in the post-natal and 9 in the pre-natal period. It was observed that of the 48 post-natal maternal deaths, enroute to the health facility and at the health facility were 13 (27\%) and 23 (48\%) respectively. In terms of place of delivery among the post-natal maternal deaths, the deliveries took place at home $24(50 \%)$ and at health facility 23 (48\%) (Figure 2).

Time is an important factor during obstetric emergencies. Hence it is important to understand the time taken by the family to arrange a transport and time taken to reach to a health facility. Table 3 elucidates that, $25 \%$ of the women were taken to one facility, $32 \%$ were taken to two facilities, and $25 \%$ taken to three facilities, while $19 \%$ were not taken to any facility before 
Table 1. Snapshot of ambulance availability in 15 public health facilities in Unnao district, UP, 2010

\begin{tabular}{|c|c|c|c|c|c|c|}
\hline No. & $\begin{array}{l}\text { Name and type of health } \\
\text { facility in Unnao district }\end{array}$ & $\begin{array}{c}\text { IPHS recommended } \\
\text { number of } \\
\text { ambulances }\end{array}$ & $\begin{array}{c}\text { No. of } \\
\text { ambulances } \\
\text { available }^{\mathrm{a}}\end{array}$ & $\begin{array}{l}\text { No. of drivers } \\
\text { working }\end{array}$ & $\begin{array}{c}\text { Adequate funds } \\
\text { available to support } \\
\text { skeletal services }^{\text {b }}\end{array}$ & $\begin{array}{l}\text { Fully functional } \\
\text { ambulance services for } \\
24 \times 7 \text { referral transport }\end{array}$ \\
\hline 1 & Asoha block PHC & 1 & 0 & 0 & No & No \\
\hline 2 & Auras block PHC & 1 & 1 & 1 & No & No \\
\hline 3 & Bangarmao $\mathrm{CHC}$ & 1 & 1 & 1 & Yes & No \\
\hline 4 & Bichiya block PHC & 1 & 0 & 1 & No & No \\
\hline 5 & Bighapur block PHC & 1 & 0 & 0 & No & No \\
\hline 6 & Fathepur Chaurasi block PHC & 1 & 0 & 0 & No & No \\
\hline 7 & Ganj Moradabad block PHC & 1 & 1 & 0 & Yes & No \\
\hline 8 & Hasanganj FRU & 2 & 1 & 1 & Yes & No \\
\hline 9 & Hilauli block PHC & 1 & 1 & 1 & Yes & No \\
\hline 10 & Miyaganj $\mathrm{CHC}$ & 1 & 0 & 1 & No & No \\
\hline 11 & Nawabganj FRU & 2 & 1 & 1 & Yes & No \\
\hline 12 & Purva $\mathrm{CHC}$ & 1 & 1 & 0 & Yes & No \\
\hline 14 & Sumerpur block PHC & 1 & 0 & 0 & No & No \\
\hline 15 & Unnao district hospital & 3 & 2 & 1 & Yes & No \\
\hline Total & & 19 & 10 & 9 & 8 & 0 \\
\hline
\end{tabular}

UP= Uttar Pradesh; IPHS= Indian Public Health Standards; PHC= Primary Health Center; CHC= Community Health Center; FRU= First Referral Unit

aAvailability does not indicate the actual working status of ambulances. Some facilities' ambulances needed repair.

bSkeletal services means that there were sufficient funds to support maintenance of the number of ambulances available, fuel costs, and the salary or contract of at least 1 driver per ambulance during the time of the study in 2010.

'Fully functional ambulance services means the availability of the IPHS recommended number of ambulances, adequate funds budgeted for maintenance and fuel costs anticipated for the year, and salaries or contracts for 3 drivers per ambulance-enabling three driving shifts covering 24 hours a day.

Table 2. Demographics of the deceased women in MDR study, Unnao district, UP, India, 2010

\begin{tabular}{llcc}
\hline \multirow{2}{*}{ Characteristics } & & \multicolumn{2}{c}{ Total (n= 57) } \\
\cline { 3 - 4 } & & Number & Percent \\
\hline Women's age at death & $<25$ & 15 & 26.3 \\
(years) & $\geq 25$ & 42 & 73.7 \\
Women's age at marriage & $<18$ & 16 & 28.1 \\
(years) & $>18$ & 41 & 71.9 \\
Women's education & Illiterate & 31 & 54.4 \\
& Literate & 13 & 22.8 \\
& Do not know & 13 & 22.8 \\
Husband's education & Illiterate & 26 & 45.6 \\
& Literate & 29 & 50.9 \\
\multirow{2}{*}{ Religion } & Do not know & 02 & 3.5 \\
& Hindu & 56 & 98.2 \\
Caste & Muslim & 01 & 1.8 \\
& Scheduled castes* & 25 & 43.9 \\
\hline
\end{tabular}

UP = Uttar Pradesh

* "Scheduled castes" and "Scheduled tribes" are historically disadvantaged communities.

their death. About $47 \%$ of the maternal deaths took place in a facility, $30 \%$ enroute to a health facility and $23 \%$ at home.

The mean time to make arrangements or preparation for travel: from home to facility 1 was 3.1 hours, from facility 1 to facility 2 was 9.9 hours and facility 2 to facility 3 was 3.1 hours. The median distance from home to facility was $11 \mathrm{~km}$, from facility 1 to facility 2 was $31.5 \mathrm{~km}$ and facility 2 to facility 3 was $25 \mathrm{~km}$ and median duration of stay in facility 1 and facility 3 was 3.1 hours, and in facility 2 was 9.9 hours. Whereas, mean travel time between facility 1 , facility 2 and facility 3 is 1.3 hours (Figure 3).

The utilization of public ambulances in Unnao district was very limited. The predominant mode of transportation from home to facility 1 was taxi/auto/truck (45\%), facility 1 to facility $2(69 \%)$ and facility 2 to facility $3(67 \%)$. Ambulance was used in only $25 \%$ of cases to transfer from facility 2 to facility 3. Only in five referred cases (13\%), families reported use of public ambulance from facility 1 to facility 2 and from

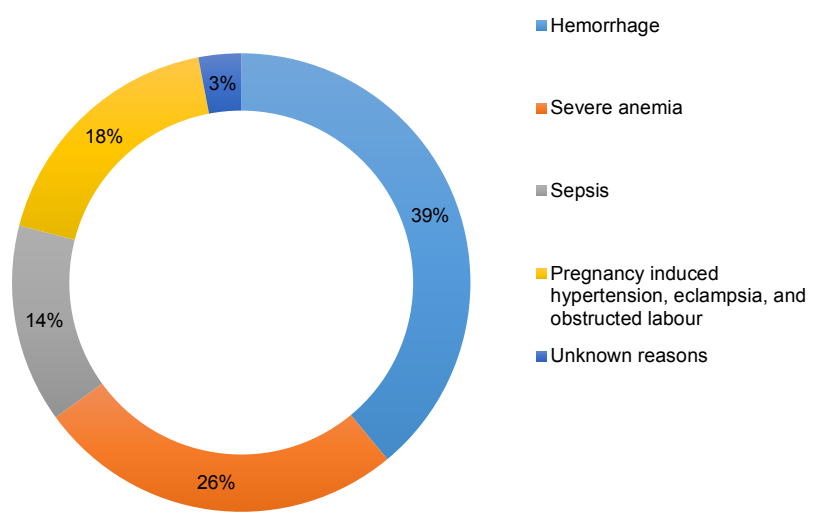

Figure 1. Causes of maternal deaths, Unnao distrcit, Uttar Pradesh (UP), $2010(n=57)$

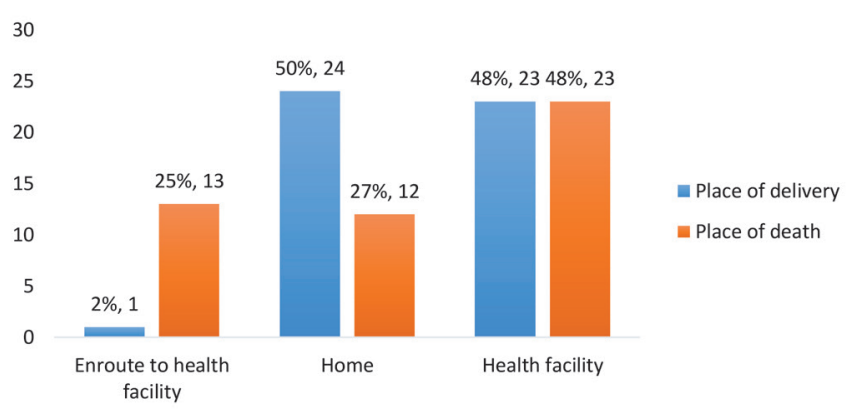

Figure 2. Place of delivery and place of death of pregnant women, Unnao distrcit, Uttar Pradesh (UP), $2010(n=48)$ 
Table 3. Pregnant women taken to formal health facility before death and place of death in Unnao District, UP, 2010 ( $n=57)$

\begin{tabular}{|c|c|c|c|c|c|}
\hline Place of death & Taken to 1 facility (\%) & Taken to 2 facilities (\%) & Taken to 3 facilities (\%) & Not taken any facility (\%) & Total (\%) \\
\hline Home to facility 1 & $6(42.8)$ & $0(0.0)$ & $0(0.0)$ & $0(0.0)$ & $6(10.5)$ \\
\hline Facility 1 to facility 2 & $0(0.0)$ & $9(50.0)$ & $0(0.0)$ & $0(0.0)$ & $9(15.7)$ \\
\hline Home & $1(7.1)$ & $0(0.0)$ & $1(7.1)$ & $11(100.0)$ & $13(22.8)$ \\
\hline Hospital & $7(50.0)$ & $9(50.0)$ & $11(78.5)$ & $0(0.0)$ & $27(47.3)$ \\
\hline Total (\%) & $14(25.0)$ & $18(32.0)$ & $14(25.0)$ & $11(19.0)$ & $57(100.0)$ \\
\hline
\end{tabular}

UP= Uttar Pradesh

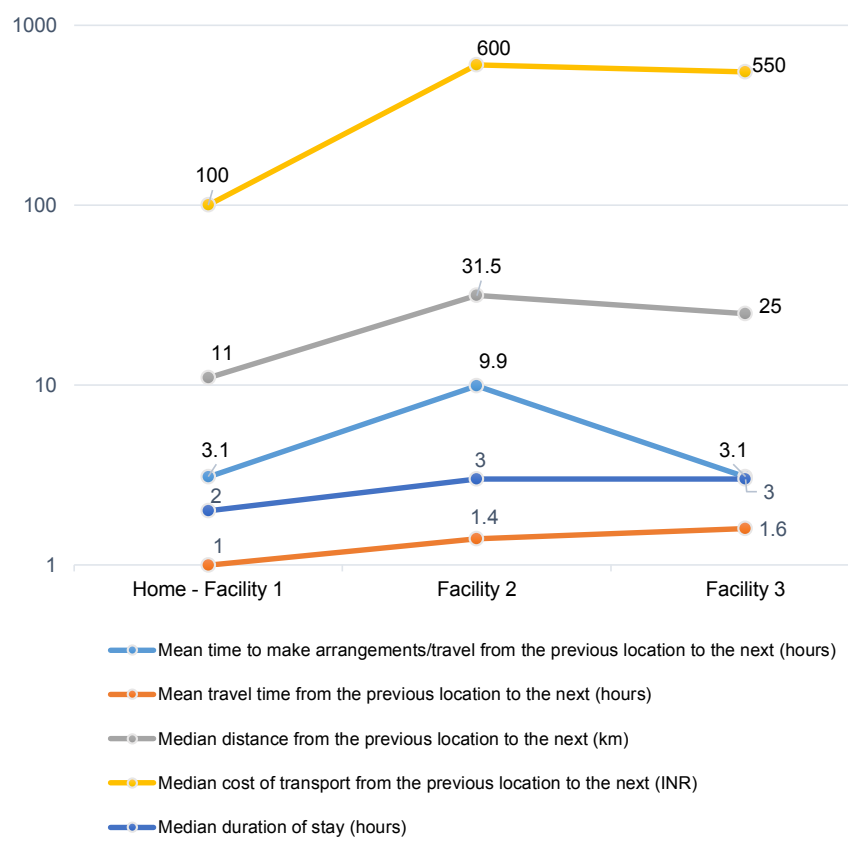

Figure 3. Delay factors, Unnao district, 2010

facility 2 to facility 3. Most of the families (97\%) used private transportation - either arranged through friends or neighbors, or a hired private taxi/truck, to take the woman from the home to the first health facility and if required to a second facility. Sixteen percent of the pregnant women could not arrange transportation to reach any facility (Table 4).

\section{Discussion}

In this study, we would like to discuss the findings mainly in the context of availability, accessibility and preparedness of referral transport in Unnao district, UP. To prevent maternal deaths, due to second delay, Government of UP needs to improve public referral transport system to help women in need to reach a health facility in time.

The IPHS guidelines envisage availability of three ambulances at the larger district hospitals, two ambulances at FRUs, and one ambulance at each CHC and block PHC (26-28). According to the facility review conducted in 16 health facilities, $26 \%$ of the healthcare facilities did not have referral transport. Around $46 \%$ had referral transport and at least one driver to operate and the remaining $26 \%$ had either an ambulance or driver. The facility review also revealed that none of the health facility had fully functional round the clock referral transport. Although IPHS guidelines are unclear about the number of drivers to be hired per ambulance but most interpret the guidelines to assume that one driver per ambulance is sufficient, however if 24-hour services are required, then there should be three drivers available per ambulance.

In this study, all the health facilities assessed were public health facilities but private hospitals were not assessed, as we could not identify any maternal deaths in the private hospitals during the study period. However, we consider this as one of the limitations of this study. This we felt for the reason that most of the private hospitals refer the pregnant women or mother to a district hospital in a pre-terminal stage. Hence no deaths were reported in private hospital. Also private hospital were extremely reluctant for facility assessment for commercial reasons.

Based on the IPHS guidelines, Unnao district, should have 22 ambulances and 66 drivers to be available at district hospital, CHC's/FRUs, and all block PHCs functioning 24 hours a day. Statewide ${ }^{1}$, for public referral transport services to be available 24 hours a day would require at least 216 ambulances at all district hospitals, 802 ambulances at CHCs/FRUs and 1,680 ambulances at the state's block PHCs (functioning $24 \times 7$ ), a total of 2,698 vehicles (9). A mechanism to efficiently utilize available functional transport services needs to be evolved. To staff these vehicles round the clock, support for 8,094 drivers would be required. The regular maintenance of ambulances,

Table 4. Mode of transportation used in the referrals in Unnao District, UP, 2010.

\begin{tabular}{|c|c|c|c|}
\hline & Home - facility 1 ( $n=48)$ & Facility 1 - facility $2(n=26)$ & Facility 2 - facility $3(n=12)$ \\
\hline Walk & $3(6.3)$ & $0(0.0)$ & $0(0.0)$ \\
\hline Rickshaw & $4(8.3)$ & $1(3.9)$ & $1(8.3)$ \\
\hline Bus & $2(4.2)$ & $1(3.9)$ & $0(0.0)$ \\
\hline Taxi/auto/truck & $22(45.8)$ & $18(69.2)$ & $8(66.7)$ \\
\hline Ambulance & $0(0.0)$ & $2(7.7)$ & $3(25.0)$ \\
\hline Could not arrange & $8(16.7)$ & $0(0.0)$ & $0(0.0)$ \\
\hline Total (\%) & $48(100.0)$ & $26(100.0)$ & $12(100.0)$ \\
\hline
\end{tabular}

UP= Uttar Pradesh

*Others includes motorized two wheelers 
fuel costs, and salaries of 3 drivers per ambulance must be a part of the state health department annual budget. This could either be a part of state budget or contract out to private firms to manage public referral transport services $(29,30)$.

As per IPHS guidelines, in all the 15 health facilities put together there should be 19 ambulances, the study findings indicates availability of only 10 ambulances with 9 drivers and in seven health facilities there was no adequate funds to support the skeleton services. Towards the end not even a single health facility equipped with $24 \times 7$ fully functional referral transport to service the pregnant women. A referral transport system must be managed professionally so that some basic interventions can be administered to patients even before they reach a health facility (31). The state government does not have any referral guidelines or standard protocols, to be followed by the CHCs or district hospital. There is no formal training on referral or transport management for doctors, nurses or drivers. There is no set system for recording the in-and-out referrals, hence no analysis could be done on referrals to facility level. Since Unnao is one of the districts in UP and it cannot have its only policies and guidelines, the recommendations for the state would also hold good for the district as well. Ideally, professionally trained paramedic staff should be available to provide basic, lifesaving interventions until the patient reaches a health facility (32). Drivers and any accompanying paramedic staff also must have the means to communicate with health facilities and vice versa (12).

Having ambulances, staff and support, and a referral transport system for accessing ambulances are all necessary but not sufficient to ensure an effective referral transport system. In the present study the public referral transport was utilized only for transferring patients out of facilities rather than transferring them in. Deaths enroute to a health facility surpassed the proportion of deaths in any other category. However deaths in a health facility whether private or public contribute up to $47 \%$ of all deaths and is a subject of serious concern. Various studies have indicated that complications during pregnancy and childbirth cannot always be predicted, and they can occur to any woman regardless of her health status $(10,17)$. It is evident that $27 \%$ maternal deaths happened enroute a health facility, $25 \%$ happened at home and rest took place in hospital.

Thirty nine percent of all deaths was caused by $\mathrm{PPH}$ and there was no facility providing blood transfusion, except district hospital. Thus referring them directly to district hospital would have saved precious time and might have saved women's life as well. Hence it is important that women in need of blood transfusion should be transferred directly to a facility where this facility is available (33). It is important to ensure that ambulance services are available to the entire population of a district or state. Neither time of the emergency, nor location of the pregnant woman, or cost should be factors dissuading families from calling for public referral transport services (31). More than half of the families claim out-of-pocket expenses for transportation and medicines (25). Our study finding corroborates findings such as the reasons given by families for not seeking care; the most common reason was the lack of available transportation. There are no operational guidelines available in the state of UP that clearly define who has the authority to request or dispatch an ambulance. There is no program to inform the public or community health workers, such as ASHAs, how to request ambulances for pregnant women in emergencies.

Way forward for creating better public referral transport services in Uttar Pradesh (UP)

The referral system is an essential component of the district health systems. All the health facilities accredited for safe delivery or institutional delivery should necessarily have an assured referral transport and assured referral linkages (16). It is particularly important in pregnancy care and childbirth for providing access to EmONC (34). The three delays model provides a conceptual framework of the factors influencing the timely arrival to appropriate care in obstetric emergency (17). The reasons for second delay have been well-documented and include difficult geographical terrain, costs of transport, lack of phones, and vehicles, suboptimal distribution and location of health facilities and poor decision-making of health professionals $(35,36)$. The interventions planned by the health department need to address the above mentioned barriers first. The inter-facility transfers or the second referrals (PHC to $\mathrm{CHC}$ and $\mathrm{CHC}$ to district hospital, etc.) to be catered by government ambulances only (37). The health system may face several issues such as problem of overlapping roles and problems between government ambulances and Gunupati Venkata Krishna Emergency Management and Research Institute (GVK EMRI) referral transport services $(34,38)$. To address this issues, the government of UP may adopt any of the existing models of public referral transport system. However, it is imperative to upgrade the current emergency transport system based on existing IPHS guidelines and bridge the gap in inter-facility transport as needed for Unnao district and the state $(12,16,23,25)$. More importantly, the context and implementation of the public referral transport system should ensure accessibility, availability and readiness. In promoting the systematic development and implementation of an evidencebased public referral transport system, Government of UP could come up with its own emergency referral transport policy. To address the issue of time to reach (timeliness) long distances, Government of UP may look into the options of integrating and harmonizing various ambulance services, referral protocols and emergency response for inter-facility referrals (34). The successful stories of some referral transport in few states should be evaluated and replicated across UP (39). A PPP framework could be the best way forward for policy makers. For example, integrating hospital referral transport services as has been done in the Haryana Swasthya Vahan Sewa (HSVS) model and or local patient transport tie-ups as in the Janani Express (JE) model could be an option to provide emergency referral services for pregnant women at very affordable cost and to establish a much larger range of patient transport services without adversely affecting GVK EMRI services $(37,40,41)$. Each of these referral transport services has its positive points as well as drawbacks. For example, the JE ensures referral transportation only, and driver of the vehicle is key person in the whole process. The drawbacks are, drivers are not trained in handling medical emergencies and vehicle is not equipped to provide any medical facility $(42,43)$. Therefore, given resource constraints, the Government of Uttar Pradesh (GoUP), can adapt an efficient referral transport model(s) along with existing ambulance services in the state with specific focus on emergency obstetric and newborn care.

The future research should be benefitting pregnant women 
and decrease the likelihood of maternal deaths during transit, and these interventions need to be further evaluated (12). The emergency obstetric referral interventions on maternal mortality in developing countries settings has better utilized healthcare facilities, but averting maternal deaths was unclear (44). This is a grey area for further research in referral transport system in the context of India. Operations research would be helpful in developing effective tools for integrating and scaling up of these interventions in various states in India. The recently developed emergency referral transport system in UP needs continuous monitoring and evaluation to improve its effectiveness, efficiency and governance.

\section{Limitation of the study}

The MDR can tell us a great deal about the process leading to maternal deaths and yet it cannot tell us much about the level and medical causes of maternal deaths for comparison among sites or over time (45). A related limitation of the MDR, concerns the distribution of clinical causes of maternal death. Another drawback is that information about reasons for delay comes from key informants such as family members, who might be less likely to attribute delays in seeking services to reluctance on the part of the family. In our study, we know that the stated cases are not representative of all maternal deaths, because no abortion-related deaths were identified. There may also be other, less obvious biases. Besides that, we obtained information from only one-third of identified maternal deaths. Nonetheless, the cases we followed were selected randomly from the sample of identified maternal deaths, and our findings on reasons for delay were so consistent that we believe they can be generalised to Unnao district.

\section{Conclusion}

The public health facility review and MDR, clearly indicates that the inter-facility transfers appropriateness and timeliness of referral are major contributing factor for maternal deaths in Unnao district, UP. Addressing this may avert a significant proportion of maternal deaths. The existing referral transport model in UP does not offer inter-facility transport services for the obstetric emergency or any other emergency. Besides of strengthening EmONC and BEmONC services in the district and state as a whole, the UP health department also needs to focus on developing a functional and effective referral system on a priority basis to reduce the maternal mortality rate in the state and nationally.

\section{Acknowledgements}

We are grateful to those family members of deceased women who participated in this study. We appreciate all those staff members of NRHM, who guided us and facilitated to carry out the facility review and the community maternal death review. We express thanks to all those ASHAs, ANMs including AWWs, who identified and reported maternal deaths for this study. We also thank Ms. Laura Barnitz for diligent review of the manuscript, further given critical feedback, and this helped us to strengthen the content of this paper. Furthermore, we would like to acknowledge USAID-India, for granting financial assistance to this research study through MCH-STAR initiative.

\section{Endnotes}

1. Currently there are 72 district hospitals, $515 \mathrm{CHC}$ (of them $287 \mathrm{CHCs}$ designated as FRUs) and 3,692 PHCs (of them 1,680 are functioning 24×7) functioning in Uttar Pradesh (as of March, 2011). (Source: NRHM State Data Fact Sheet for March, 2011 and DLHS-3, 2007-08, IIPS).

\section{Ethical issues}

Approval for the study was obtained by the Institutional Ethics Committee of the Indian Institute of Public Health, Delhi. All interviews were conducted after obtaining written consent from the family.

\section{Competing interests}

The authors declare that they have no competing interests.

\section{Authors' contributions}

SSR was responsible for concept and design, acquisition of data, data analysis, interpretation, and drafting the article. SM was responsible for data analysis, interpretation and drafting the article. PKS was involved in concept and design, acquisition of data and drafting of the article.

\section{Authors' affiliations}

${ }^{1}$ HIVIAIDS Partnership for Impact through Prevention, Private Sector and Evidence-based Programming (PIPPSE) Project, Public Health Foundation of India, New Delhi, India. ${ }^{2}$ Health Promotion Division, Public Health Foundation of India, New Delhi, India.

\section{References}

1. World Health Organization (WHO), United Nations Population Fund (UNFPA), Children's Rights and Emergency Relief Organization (UNICEF) and The World Bank estimates. Trends in maternal mortality: 1990 to 2010 [Internet]. WHO; 2012. [cited 28 Nov 2014]. Available from: http://whqlibdoc.who.int/ publications/2012/9789241503631_eng.pdf?ua=1

2. Lozano R, Wang H, Foreman KJ, Rajaratnam JK, Naghavi M, Marcus JR, et al. Progress towards Millennium Development Goals 4 and 5 on maternal and child mortality: an updated systematic analysis. Lancet 2011; 378: 1139-65. doi: 10.1016/ S0140-6736(11)61337-8

3. Trends in Maternal Mortality: 1990 to 2013 [Internet]. World Health Organization; 2014. [cited 2014 Nov 24]. Available from: http:// apps.who.int/iris/bitstream/10665/112697/1/WHO_RHR_14.13_ eng.pdf

4. Registrar General, India. SRS Bulletin, Sample Registration System. New Delhi: Office of the Registrar General, Ministry of Home Affairs, Government of India; 2012.

5. Lim SS, Dandona L, Hoisington JA, James SL, Hogan MC, Gakidou E. India's Janani Suraksha Yojana, a conditional cash transfer programme to increase births in health facilities: an impact evaluation. Lancet 2010; 375: 2009-23. doi: 10.1016/ S0140-6736(10)60744-1

6. National Rural Health Mission, Ministry of Health and Family Welfare, Government of India. Third Common Review Mission Report. New Delhi, India; 2009.

7. National Family Health Survey - 3 [Internet]. International Institute of Population Sciences; 2005-06. [cited 2013 Jan 10]. Available from: http://www.rchiips.org/NFHS/pdf/Uttar\%20Pradesh.pdf

8. Project Implementation Plan: Uttar Pradesh Health Systems Strengthening Project [Internet]. Department of Medical Health and Family Welfare, Government of Uttar Pradesh; 2011. [cited 2013 Sep 15]. Available from: http://uphealth.up.nic.in/uphssp/ documents/Revised_PIP_Final_30_AUG_2011_version.pdf

9. Rural Health Statistics in India, 2011 [Internet]. National Rural Health Mission, Ministry of Health and Family Welfare, Government of India; 2011. [cited 2013 Feb 10]. Available from: http://nrhm-mis.nic.in/Ul/RHS/RHS\%202011/RHS\%20 -March\%202011-\%20Tables-\%20Final\%209.4.2012.pdf

10. World Health Organization (WHO), United Nations Population Fund (UNFPA), Children's Rights and Emergency Relief Organization (UNICEF) and Averting Maternal Death and Disability (AMDD). Monitoring emergency obstetric care: a 
handbook. Geneva: WHO; 2009.

11. Ministry of Health and Family Welfare (MoHFW). National Rural Health Mission (NRHM): Mission Document. New Delhi: Ministry of Health and Family Welfare; 2005.

12. Operating perinatal referral transport services in rural India: a tool kit [Internet]. UNICEF; 2010. [cited 2013 August 15]. Available from: http://www.unicef.org/india/Referral_Transport_bookFinal_PDF.pdf

13. Technical report on Improving Transportation and Referral for Maternal Health: Knowledge Gaps and Recommendations [Internet]. Wilson Center; 2010. [cited 2013 Sep 9]. Available from: http://www.wilsoncenter.org/sites/default/files/Transport\%20 Referral\%20Meeting\%20Technical\%20Report.pdf

14. Potluri P. Emergency Services in India: Counting on betterment. Asian Hospital and Healthcare Management [serial on the Internet]. 2009. Available from: http://www.asianhhm.com/ healthcare_management/emergency_services_india.htm

15. Yousuf AM. Emergency healthcare: Taking off to the next level. Modern Medicare [serial on the Internet]. 2011. Available from: http://modernmedicare.co.in/articles/emergency-healthcaretaking-off-to-the-next-level/

16. Ministry of Health and Family Welfare (MoHFW), Government of India. Operational Guidelines on Maternal and Newborn Health. New Delhi: NRHM, MoHFW; 2010.

17. Maine D. Safe Motherhood Programs: Options and Issues. Center for Population and Family Health. New York: Columbia University; 1991. p. 42-51.

18. Special bulletin on maternal mortality in India: 2007-2009 [Internet]. Office of Registrar General, India, Ministry of Home Affairs, Government of India; June 2011. [cited 2013 Feb 10]. Available from: http://www.censusindia.gov.in/vital statistics/ SRS_Bulletins/Final-MMR\%20Bulletin-2007-09_070711.pdf

19. Jansankhya Sthirta Kosh: National Population Stabilisation Fund. District level health facility GIS maps and indices [Internet]. Jansankhya Sthirta Kosh; 2007. [cited 2012 Nov 20]. Available from: http://www.jsk.gov.in/district_health.asp

20. Census of India [Internet]. Ministry of Home Affairs, Government of India; 2011. [cited 2013 Feb 12]. Available from: http://www. censusindia.gov.in/2011-prov-results/paper2/census2011_ paper2.html

21. Sample Registration System [Internet]. Ministry of Home Affairs, Government of India; 2012. [cited 2013 Jan 20]. Available from: http://www.censusindia.gov.in/vital_statistics/SRS_Bulletins/ SRS_Bulletin-October_2012.pdf

22. Ministry of Health and Family Welfare (MoHFW). About Accredited Social Health Activist (ASHA) [internet]. National Health Mission; 2013. [cited 2014 Dec 10]. Available from: http://nrhm.gov.in/ communitisation/asha/about-asha.html

23. Maternal and Child Health Sustainable Technical Assistance and Research (MCH-STAR) Project, USAID. Technical Assistance to the Government of Jharkhand to Operationalize First Referral Units (FRUs) [internet]. 2010. [2012 Nov 30]. Available from: http://www.mchstar.org/technicalAssistance/projects/ communicationCampaign.htm

24. Maternal and perinatal death inquiry and response: empowering communities to avert maternal deaths in India [Internet]. UNICEF; 2009 [cited 2013 Sep 15]. Available from: http://www.mapedir.org/ MDAC-Maternal.pdf

25. Raj SS, Maine D, Sahoo PK, Manthri S, Chauhan K. Meeting the community halfway to reduce maternal deaths? Evidence from a community-based maternal death review in Uttar Pradesh, India. Global Health: Sci Pract 2013; 1: 84-96. doi: 10.9745/ GHSP-D-12-00049

26. Guidelines for operationalising First Referral Units [Internet]. Ministry of Health and Family Welfare, Government of India; 2004. [cited 2015 Jan 7]. Available from: http://www.medbox.org/ in-nh-guides/guidelines-for-operationalising-first-referral-units/ preview?q=

27. Indian Public Health Standards (IPHS) Guidelines for Community
Health Centers, Revised 2012 [Internet]. Directorate General of Health Services, Ministry of Health and Family Welfare, Government of India; 2012. [cited 2015 Jan 7]. Available from: http://health.bih.nic.in/Docs/Guidelines/Guidelines-CommunityHealth-Centres.pdf

28. Indian Public Health Standards (IPHS): Guidelines for District Hospitals, Revised 2012 [nternet]. Directorate General of Health Services Ministry of Health and Family Welfare, Government of India; 2012. [cited 2015 Jan 7]. Available from: http://health.bih. nic.in/Docs/Guidelines/Guidelines-District-Hospitals-2012.pdf

29. Rogi Kalyan Samities/Hospital Management [Internet]. National Rural Health Mission; 2012. [cited 14 November 2012]. Available from: http://mohfw.nic.in/NRHM/RKS.htm\#intro

30. Emergency Medical Service (EMS) in India: a concept paper [Internet]. National Health Systems Resource Centre; 2011. [cited 2013 Sep 15]. Available from: http://nhsrcindia.org/pdf_files/ resources thematic/Financing and PPP/NHSRC_Contribution/ Others/EMS_Concept_Paper.pdf

31. Murray SF, Pearson SC. Maternity referral systems in developing countries: current knowledge and future needs. Soc Sci Med 2006; 62: 2205-15. doi: 10.1016/j.socscimed.2005.10.025

32. Evaluation Study of National Rural Health Mission (NRHM) in 7 States [Internet]. Planning Commission, India; 2011. [cited 2013 Sep 15]. Available from: http://planningcommission.nic.in/reports/ peoreport/peoevalu/peo_2807.pdf

33. Sahoo Pk, Raj SS, Manthri S. Improved access to safe blood must be prioritized as a core component of comprehensive efforts to prevent maternal deaths in Uttar Pradesh, India. Int J Med Sci Public Health 2014; 3: 1208-14.

34. Gupta M, Mavalankar D, Poonam Trivedi. A study of referral system for EmOC in Gujarat. Research and publications: Working paper series; 2009.

35. Thaddeus S, Maine D. Too far to walk: maternal mortality in context. Soc Sc Med 1994; 38: 1091-110. doi: 10.1016/02779536(94)90226-7

36. Jahn A, de Brouwere $\mathrm{V}$. Referral in pregnancy and childbirth: concepts and strategies. In: Brouwere VD, Lerberghe W V, editors. Safe motherhood strategies : a review of the rvidence. Antwerp, Belgium: ITG Press; 2001.

37. Sundararaman T, Chakraborty G, Nair A, Mokashi T, Ved R. Publicly Financed Emergency Response and Patient Transport Systems Under NRHM. National Health Systems Resource Centre, New Delhi (India); 2012.

38. Murray SF, Davis S, Phiri KR, Ahmed Y. Tools for monitoring the effectiveness of district maternity referral systems. Health Policy Plan 2001; 16: 353-61.

39. Publicly Financed Emergency Response and Patient Transport Systems Under NRHM. National Health Systems Resource Centre; 2012.

40. Prinja S, Manchanda N, Aggarwal AK, Kaur M, Jeet G, Kumar R. Cost \& efficiency evaluation of a publicly financed \& publicly delivered referral transport service model in three districts of Haryana State, India. Indian J Med Res 2013; 138: 1003-11.

41. Sundararaman T, Nair A, Mokashi T, Chakraborthy G. Business models of public private partnerships in publicly-financed emergency response services. BMC Proc 2012; 6: P8. doi: 10.1186/1753-6561-6-S5-P8

42. Documentation of "JE Management Models by SHG, Federations and NGO" in Orissa. National Rural Health Mission; 2011.

43. Prinja S, Jeet G, Kaur M, Aggarwal AK, Manchanda N, Kumar R. Impact of referral transport system on institutional deliveries in Haryana, India. Indian J Med Res 2014; 139: 883-91.

44. Hussein J, Kanguru L, Astin M, Munjanja S. The Effective of Emergency obstetric Referral Interventions in Developing Country Settings: A Systematic Review. PLoS Med 2012; 9: e1001264. doi: 10.1371/journal.pmed.1001264

45. Sloan NL LA, Hernandez B, Romero M, Winikoff B. The etiology of maternal mortality in developing countries: what do verbal autopsies tell us? Bull World Health Organ 2001; 79: 805-10. 